\title{
OPINION
}

\section{De rampzalige invloed van Ronald Dworkin op het Nederlandse euthanasierecht}

\author{
Klaas Rozemond
}

Ronald Dworkin was een van de belangrijkste rechtsfilosofen van zijn tijd. Zijn opvattingen over rechten en beginselen, constructieve interpretatie, integriteit en gelijkwaardigheid hebben nog steeds een grote invloed op rechtsfilosofen en juristen. Dat is volkomen terecht, ook al hoef je het niet op alle punten met hem eens te zijn. Het zou ook wonderlijk zijn als een rechtsfilosoof alleen maar juiste antwoorden heeft gegeven op de moeilijke rechtsvragen waarmee we nog steeds worstelen. Recht is een argumentatieve praktijk en de rechtsfilosofie is dat ook. De opvattingen van Dworkin moeten daarom, geheel volgens zijn eigen principes, kritisch worden getoetst om te onderzoeken of ze wel juist zijn (dat geldt natuurlijk ook voor wat hierna volgt). In deze bijdrage wil ik onderzoeken of de opvattingen van Dworkin over euthanasie en dementie juist zijn, vooral omdat ze zo'n grote invloed hebben op het euthanasierecht in Nederland. Zijn opvattingen zouden wel eens beslissend kunnen zijn in de zaak van de verpleeghuisarts die het leven van een patiënte met dementie beëindigde, waarover de Hoge Raad binnenkort uitspraak doet.

In zijn opvattingen over euthanasie gaat Dworkin ervan uit dat ieder mens twee soorten belangen heeft: ervaringsbelangen (experiental interests) en kritische belangen (critical interests). ${ }^{1}$ De ervaringsbelangen betreffen positieve ervaringen in allerlei varianten, van platvloerse spelletjes tot poëzie. De kritische belangen zijn gebaseerd op de waarden die mensen met hun verstandelijke vermogens aan hun leven toekennen. In ieder mens zit een genotselement en een rationeel element en die twee samen bepalen wat de waarde van zijn of haar leven is. Het rationele element is volgens Dworkin de beslissende instantie, omdat een mens met zijn rationele vermogens kan beoordelen wat hij of zij waardevol vindt en kan aangeven welke vormen van genot hij of zij wil ondergaan. Rationele keuzen zijn de uitdrukking van de autonomie van een persoon en persoonlijke waarden geven integriteit aan iemands leven als coherente eenheid. Met je rationele vermogens kun je ook bepalen wanneer je het leven niet meer waardevol vindt en daarom niet meer verder wilt leven.

Er is een punt waarop ik het niet helemaal eens ben met Dworkin: zijn opvatting over euthanasie bij dementie. ${ }^{2}$ Op zich vind ik zijn opvatting als persoonlijke filosofie volstrekt respectabel. Als je zelf echt in zijn filosofie gelooft, heb je het vol-

1 Dworkin, Life's Dominion (New York: Alfred J. Knopf, 1993), 201 e.v.

2 Dworkin, Life's Dominion, 218 e.v. 
ste recht om volgens die filosofie te leven. Een dworkiniaan heeft ook het fundamentele recht om als dworkiniaan te sterven. Het probleem is echter dat niet iedereen dworkiniaan is. Het gevaar van Dworkins opvatting is dat zij een constructieve interpretatie wordt van de levens van anderen waarmee zij niet hebben ingestemd. Bij gevorderde dementie kun je mensen ook niet meer vragen of ze het met een dworkiniaanse interpretatie van hun leven eens zijn. Bovendien zijn er meerdere interpretaties mogelijk van hun levens en daardoor ook van hun schriftelijke wilsverklaringen die in bepaalde gevallen op zich al meerduidig zijn. ${ }^{3}$ Als je deze mensen laat sterven volgens een interpretatie die zij zelf niet uitdrukkelijk hebben onderschreven, is het geen euthanasie, maar moord. Je kunt daarom Dworkins opvatting over euthanasie als persoonlijk principe van je eigen leven beschouwen, maar als algemeen principe van wetgeving verwerpen.

Het zelfbeschikkingsrecht houdt in dat je het fundamentele recht hebt om zelf de betekenis van je leven te bepalen. In verband met het levenseinde is dit zelfbeschikkingsrecht nadrukkelijk erkend door het Europees Hof voor de Rechten van de Mens, ${ }^{4}$ en onlangs ook door het Duitse Bundesverfassungsgericht. ${ }^{5}$ De onbeperkte strafbaarstelling van bedrijfsmatige hulp bij zelfdoding is volgens het Duitse constitutioneel hof in strijd met het zelfbeschikkingsrecht. Bij de uitoefening van dat recht geldt echter wel de voorwaarde dat de beslissing om een einde aan je leven te maken inderdaad jouw vrijwillige en weloverwogen keuze is. Het Nederlandse euthanasierecht is geen zelfdodingsrecht, maar euthanasierecht. In het overgrote deel van de bij de toetsingscommissies gemelde gevallen gaat het om euthanasie. De arts maakt door middel van het toedienen van een dodelijk middel een einde aan het leven van een patiënt die daartoe het verzoek heeft ingediend omdat hij ondraaglijk lijdt ten gevolge van een ziekte. Wanneer deze patiënt ook zelfdoding had kunnen plegen in de vorm van een bewuste handeling om een dodelijke middel in te nemen, is er geen principieel verschil tussen hulp bij zelfdoding en euthanasie. De keuze van de arts en de patiënt tussen euthanasie en hulp bij zelfdoding heeft vooral te maken met een zorgvuldige uitvoering: bij euthanasie is de kans kleiner dat het misgaat. Er kan ook een fysieke reden zijn voor euthanasie: de patiënt is fysiek niet meer in staat om zelf het dodelijke middel in te nemen, bijvoorbeeld bij de spierziekte ALS waardoor iemand volledig verlamd raakt.

Het verschil tussen hulp bij zelfdoding en euthanasie is echter wel relevant in de gevallen waarin mensen door psychische oorzaken niet meer in staat zijn om zelfdoding te plegen, bijvoorbeeld mensen met vergevorderde dementie. Deze mensen begrijpen niet meer wat zelfdoding is en ze kunnen daarom ook niet meer bewust een dodelijk middel innemen met het doel om zelf een einde aan hun leven te maken. Om die reden is in Nederland euthanasie bij deze mensen mogelijk op grond van een schriftelijke wilsverklaring die ze hebben opgesteld

3 Er zijn ook meerdere interpretatietheorieën, waarvan die van Dworkin er een is. Daardoor kan een veelvoud van interpretaties ontstaan die wordt vermeden wanneer de betrokkene zelf nog moet kunnen aangeven wat de beste interpretatie van zijn of haar leven is.

4 EHRM 20 januari 2011, No. 31322/07 (Haas/Zwitserland).

5 BVerfG 26 februari 2020, ECLI:DE:BVerfG:2020:rs20200226.2bvr2347. 
toen ze nog wel in staat waren om hun wil te bepalen. In Duitsland is dit nadrukkelijk verboden: artsen mogen geen euthanasie plegen op psychogeriatrische patiënten en dat heeft een historische achtergrond in het nazi-verleden.

De opvatting van Dworkin gaat nog verder dan wat het Nederlandse euthanasierecht al toestaat. Dworkin was van mening dat euthanasie zelfs mogelijk moet zijn wanneer een patiënt met dementie op het moment van levensbeëindiging geen euthanasie wil omdat hij zich goed voelt. Op grond van de ervaringsbelangen van deze persoon zou je zeggen dat euthanasie dan ook niet mag en zo is het in Nederland geregeld: deze persoon lijdt niet ondraaglijk en wil om die reden niet dood. Dworkin betoogde echter dat de wil van de wilsbekwame persoon zwaarder weegt dan de wil van de wilsonbekwame persoon. Je respecteert de autonomie van deze persoon niet wanneer je hem laat leven in een toestand die hij niet wilde toen hij nog over al zijn geestelijke vermogens beschikte. Je mag hem op morele gronden doden, ook al wil die persoon dat op dat moment niet. ${ }^{6}$

Deze opvatting van Dworkin is om meerdere redenen problematisch. Allereerst getuigt zijn opvatting van een overschatting van de rationele vermogens van mensen. Zijn opvatting is gebaseerd op de gedachte dat mensen op het moment dat ze hun schriftelijke wilsverklaring opstellen, kunnen voorzien wat ze voor de toekomst willen op grond van de waarden waarmee ze een eenduidige betekenis aan hun leven kunnen geven. Zelfs de meest rationele mensen beschikken niet over zo'n definitief bepaalde wil, omdat ze geen volmaakt inzicht hebben in hun diepste verlangens en hun toekomstige ervaringen. Daarom passen mensen hun wil aan wanneer bepaalde omstandigheden veranderen. Dworkins idee van morele integriteit past niet bij mensen die hun opvattingen bijstellen naar aanleiding van ervaringen die ze nog niet eerder hebben gehad.

Dat geldt niet alleen voor mensen met een psychische ziekte die hun rationele vermogens aantast, maar ook voor mensen met een fysieke ziekte zoals ALS. Deze patiënten regelen vaak dat ze euthanasie kunnen krijgen wanneer ze in een verpleeghuis moeten worden opgenomen. Wanneer het zover is, schuiven ze soms het moment van euthanasie voor zich uit omdat ze toch verder willen leven. Het is zelfs mogelijk dat iemand door dergelijke ingrijpende levenservaringen van filosofie verandert. De dworkiniaan met ALS kan hedonist worden wanneer hij merkt dat hij nog steeds positieve ervaringen heeft, ook al stroken die ervaringen niet met de vroegere waardering van zijn leven.

Dat kan ook gebeuren bij mensen met dementie. Zij kunnen hun wil aanpassen wanneer ze in een verpleeghuis terechtkomen, ook al hebben zij in hun schriftelijke verklaring aangegeven dat ze juist niet willen worden opgenomen en dan liever euthanasie willen. Op het moment dat mensen met dementie daadwerkelijk voor de keuze worden gesteld, kiezen ze in bepaalde gevallen toch voor het leven in plaats van de dood. Dat is een begrijpelijke en menselijke keuze. Het is ook een vrijwillige keuze. Er is juridisch gezien geen sprake van een dwangopname, maar van een vrijwillige opname wanneer mensen voor opname kiezen in plaats van euthanasie. Naar Nederlands recht zijn deze mensen wilsbekwaam ten aanzien 
van deze keuze. ${ }^{7}$ Psychogeriatrische cliënten beslissen in beginsel zelf over de zorg die aan hen wordt verleend en dat geldt ook voor de opname in een verpleeghuis. $^{8}$

Het zelfbeschikkingsrecht van psychogeriatrische patiënten betekent ook dat ze het fundamentele recht hebben om voor de dood te kiezen wanneer zij hun lijden ondraaglijk vinden. Volgens het jaarverslag over 2018 van de Regionale Toetsingscommissies Euthanasie werden in dat jaar 146 gevallen als zorgvuldig beoordeeld waarin mensen met dementie euthanasie hadden gekregen. ${ }^{9}$ In 144 gevallen waren deze mensen volgens de artsen en de toetsingscommissies wel wilsbekwaam en konden zij ook aangeven dat ze ondraaglijk leden door hun ziekte. Het is dus mogelijk dat mensen met dementie vrijwillig en weloverwogen voor de dood kiezen, ook al hebben ze geen schriftelijke wilsverklaring, hoewel een dergelijke verklaring hun keuze wel kan ondersteunen. ${ }^{10}$

Hoeveel mensen met een schriftelijke wilsverklaring uiteindelijk toch niet voor de dood kiezen, maar voor opname in een verpleeghuis, is onbekend. Als je de filosofie van Dworkin volgt, zou een verpleeghuisarts deze mensen wel mogen doden. Deze patiënten kiezen voor het leven in een situatie waarvan ze eerder schriftelijk hebben aangeven dat ze dood willen. Mogelijk hebben deze mensen positieve ervaringsbelangen, voelen ze zich goed, willen ze om die reden niet dood en kunnen ze dat ook aangeven. Volgens de dworkiniaanse opvatting over hun kritische belangen heeft hun leven echter geen waarde meer en daarom mag hun leven worden beëindigd.

Iedere psychogeriatrische patiënt met een schriftelijke wilsverklaring valt in beginsel binnen het bereik van Dworkins filosofie. Gelet op de vergrijzing van de bevolking en de populariteit van de Nederlandse Vereniging voor een Vrijwillig Levenseinde (172.000 leden) is op dit moment niet te overzien om hoeveel mensen het gaat in de nabije en verre toekomst.

Dit gevaar lijkt vergezocht, maar in de geruchtmakende zaak van de verpleeghuisarts die het leven van een patiënte met dementie beëindigde, was het al zo ver. Deze patiënte verklaarde voor en na opname in een verpleeghuis uitdrukkelijk dat zij geen euthanasie wilde en dat zij verder wilde leven met dementie. In haar schriftelijke wilsverklaring had ze bepaald dat ze juist niet in een verpleeghuis wilde worden opgenomen. Daarbij had ze echter ook het voorbehoud gemaakt dat

7 Over de wilsbekwaamheid van psychogeriatrische patiënten bestaan nog steeds veel misverstanden in de rechtspraak en de literatuur over euthanasie en dementie. Zie voor een verhelderend overzichtsartikel I.M. Hein, J. Raymaekers, E. Kres en B.J.M. Frederiks, 'Wilsbekwaamheid bij mensen met een verstandelijke beperking', Tijdschrift voor Psychiatrie, (2019): 766-772.

8 Zie artikel 7:446 en 7:450 lid 1 BW (WGBO), artikel 3 lid 1 Wet zorg en dwang psychogeriatrische en geestelijk gehandicapte cliënten en artikel 12 Verdrag inzake de rechten van personen met een handicap.

9 Jaarverslag 2018: 13. Het jaarverslag staat op www.euthanasiecommissie.nl.

10 Een extreem voorbeeld is te vinden in Oordeel 2017-14 op www.euthanasiecommissie.nl: een patiënte met vergevorderde dementie weigert plaatsing in de gesloten afdeling van een verzorgingshuis en wordt wilsbekwaam geacht ter zake van haar verzoek tot levensbeëindiging. 
ze euthanasie wilde op het moment dat ze daar zelf de tijd rijp voor achtte. ${ }^{11} \mathrm{Ze}$ voelde zich goed, zo verklaarde ze tegenover haar huisarts, en het was nog niet zo erg, zei ze tegen de verpleeghuisarts en de consulent van het Expertisecentrum Euthanasie, en daarom wilde ze nog niet dood. De huisarts en de verpleeghuisarts noteerden deze verklaringen van de vrouw in hun medische dossiers. ${ }^{12}$ De verpleeghuisarts voerde na consultatie van twee SCEN-artsen de levensbeëindiging uit door het heimelijke toedienen van een slaapmiddel in de koffie van de patiente, waarna de patiënte via een infuus een dodelijk middel kreeg toegediend waartegen zij zich fysiek verzette, zodat ze moest worden vastgehouden om de levensbeëindiging te kunnen voltooien.

De arts voerde voor haar handelwijze het argument aan dat de vrouw al voor de opname in het verpleeghuis wilsonbekwaam was geworden, ${ }^{13}$ hoewel de opname vrijwillig was en de vrouw ter zake daarvan kennelijk wel wilsbekwaam werd geacht. Zij heeft bewust gekozen voor opname in plaats van euthanasie en had daartoe het beslissingsrecht dat wordt beschermd door artikel 2 en 8 EVRM en artikel 10, 12 en 22 van het Verdrag inzake de rechten van personen met een handicap. ${ }^{14}$

Bij de toetsingscommissie en het tuchtcollege verklaarde de arts - in overeenstemming met de filosofie van Dworkin - dat zij het leven van de patiënte ook zou hebben beëindigd als de patiënte tegen haar zou hebben gezegd dat ze dat niet wilde, wat de patiënte ook daadwerkelijk tegen haar heeft gezegd. Volgens de arts kon aan de wilsverklaringen van de patiënte geen betekenis meer worden toegekend. Het Regionaal Tuchtcollege Den Haag keurde deze redenering af. ${ }^{15}$ De Rechtbank Den Haag besliste echter dat de handelwijze van de arts wel zorgvuldig was, omdat de strekking van de schriftelijke wilsverklaring volgens de rechtbank duidelijk was en de patiënte al voor opname in het verpleeghuis wilsonbekwaam

11 Om die reden vond de toetsingscommissie dat de arts onzorgvuldig had gehandeld door gevolg te geven aan de schriftelijke verklaring zonder dat de vrouw had aangegeven dat de tijd rijp was. Zie Oordeel 2016-85 op www.euthanasiecommissie.nl. In gelijke zin overweging 5.9 in Regionaal Tuchtcollege Den Haag 24 juli 2018, ECLI:NL:TGZRSGR:2018:165.

12 Zie overweging 4.4.1 in Rechtbank Den Haag 11 september 2019, ECLI:NL:RBDHA:2019:9506 en overweging 2.13 in ECLI:NL:TGZRSGR:2018:165.

13 Zie de verklaring van de arts in Oordeel 2016-85. Deze verklaring staat op gespannen voet met het Stappenplan bij beoordeling van wilsonbekwaamheid, bijlage 9 bij Implementatie van de WGBO Deel 2 - Informatie en toestemming op www.knmg.nl.

14 Zie hierover Klaas Rozemond, 'Mensen met dementie hebben het recht om euthanasie te weigeren', Nederlands Juristenblad, (2020): 292 e.v.

15 Overweging 5.10 in ECLI:NL:TGZRSGR:2018:165. Zie ook overweging 5.13 met verwijzing naar artikel 7:448 lid 1 en 7:450 lid 1 BW (WGBO) en 'de regelgeving rond dwangbehandeling en dwangmedicatie' (sinds 1 januari 2020 is dat de Wet zorg en dwang psychogeriatrische en geestelijk gehandicapte cliënten) voor het negatieve oordeel van het tuchtcollege over het heimelijke toedienen van het slaapmiddel. Ook het Stappenplan van de KNMG (Stap 4, 5, 11 en 16) sluiten de opvatting en de handelwijze van de arts uit. Zie ook Oordeel 2016-85 van de toetsingscommissie. 
zou zijn geworden. ${ }^{16}$ De procureur-generaal bij de Hoge Raad was het met de rechtbank eens onder expliciete verwijzing naar de filosofie van Dworkin. ${ }^{17}$ Opvallend afwezig in het rechtsvergelijkende overzicht van de procureur-generaal is Duitsland. ${ }^{18}$

Wat ook ontbreekt in de vorderingen van de procureur-generaal is de notie dat artsen in een democratische samenleving slechts de bevoegdheid kunnen krijgen om levens te beëindigen van bijzonder kwetsbare personen ${ }^{19}$ wanneer de uitoefening van die bevoegdheid aan zeer strikte regels is gebonden en aan een uiterst kritische toetsing wordt onderworpen. De vorderingen van de procureurgeneraal hebben precies de tegenovergestelde strekking: artsen hebben een discretionaire bevoegdheid om de levens van mensen met dementie te beëindigen en de uitoefening van die bevoegdheid kan slechts marginaal worden getoetst. ${ }^{20}$

Commentaren vanuit dworkiniaans perspectief zijn lovend over de bevoegdheid van artsen om mensenlevens te beëindigen op basis van hun constructieve interpretaties van schriftelijke wilsverklaringen. ${ }^{21}$ Vanuit dworkiniaans perspectief heeft de rechtbank de enig juiste beslissing genomen en daaruit kan worden afgeleid dat dit het dworkiniaanse precedent is voor toekomstige gevallen in verpleeg-

16 Overweging 4.4.4 en 5.3.2 in ECLI:NL:RBDHA:2019:9506. De rechtbank legt niet uit waarom de vrouw dan wel kon beslissen dat zij werd opgenomen in het verpleeghuis en de rechtbank geeft ook niet aan op welke richtlijnen haar oordeel van wilsonbekwaamheid is gebaseerd (bijvoorbeeld het Stappenplan van de KNMG). Ook de toetsingscommissie en het tuchtcollege verschaffen hierover geen helderheid.

17 Punt 1.17 in de vordering van de procureur-generaal tot cassatie in het belang der wet van 17 december 2019, ECLI:NL:PHR:2019:1338. Zie voor kritiek op de dworkiniaanse visie van de procureur-generaal Britta van Beers, 'Staat van verwarring', Ars Aequi, (2020): 146-147.

18 Overweging 3.2 e.v. in ECLI:NL:PHR:2019:1338. De procureur-generaal stipt wel heel kort de ontwikkeling in Duitsland aan in overweging 3.26, maar zonder bespreking van het principiële verschil tussen hulp bij zelfdoding en euthanasie in Duitsland. Hij bespreekt ook niet de Wet zorg en dwang psychogeriatrische en geestelijk gehandicapte cliënten, het Verdrag inzake de rechten van personen met een handicap, artikel 7:448 lid 1 en 7:450 lid 1 BW (WGBO) en het Stappenplan van de KNMG, en hij gaat niet in op de beschermende werking van artikel 2 en 8 EVRM ten aanzien van bijzonder kwetsbare personen zoals mensen met dementie. Men vergelijke overweging 4.19 over 'een ruime beoordelingsvrijheid' van staten met de kritische toetsing in overweging 103 e.v. in EHRM 31 januari 2019, No. 78103/14 (Fernandes de Oliveira/Portugal).

19 Deze term gebruikt het EHRM om mensen met een geestesziekte aan te duiden, zie overweging 113 in Fernandes de Oliveira/Portugal.

20 Zie overweging 13.16 in ECLI:NL:PHR:2019:1338. Zie ook overweging 7.3-7.5 in de vordering van 17 december 2019, ECLI:NL:PHR:2019:1339 ten aanzien van de uitspraak van het Centraal Tuchtcollege van 19 maart 2019, ECLI:NL:TGZCTG:2019 waarin het CTG het oordeel van het Regionaal Tuchtcollege bevestigde.

21 Bijvoorbeeld Govert den Hartogh, 'Euthanasie op grond van een schriftelijke wilsverklaring', Nederlands Juristenblad, (2017): 2231-2233 en 'Naar een uniforme uitleg van artikel 2 lid 2 Wtl', Nederlands Juristenblad, (2020): 756-761 van dezelfde auteur. 
huizen en daarbuiten. ${ }^{22}$ Dworkins filosofie dreigt het paradigma te worden van het Nederlandse euthanasierecht. ${ }^{23}$

Dit paradigma levert echter een filosofisch probleem op dat kan worden geillustreerd aan de hand van de feiten uit deze zaak. Het is de vraag of deze vrouw wel een aanhangster was van Dworkins opvatting over autonomie, integriteit, interpretatie en euthanasie. Het meest waarschijnlijke is dat zij niet in dworkiniaanse begrippen over haar eigen leven dacht. Wie haar schriftelijke verklaring leest, krijgt de indruk dat het bij haar ook niet om kritische belangen, maar om ervaringsbelangen ging. Haar moeder en andere familieleden waren dement en dat wilde zij beslist niet meemaken, zo schreef zij in haar emotionele wilsverklaring. Daaruit blijkt het paradoxale karakter van haar verzoek. Je maakt immers niet bewust mee dat je 'als een kasplantje' in een verpleeghuis zit. ${ }^{24}$

Dat roept de vraag op of dit wel een coherent verzoek was in de dworkiniaanse betekenis van coherentie. Deze vrouw heeft wellicht niet goed nagedacht over haar kritische belangen en haar ervaringsbelangen, want zij wilde iets niet meemaken dat zij niet kon meemaken. Kennelijk heerste bij haar de irrationele angst over het rationele oordeel in plaats van andersom. Het waren de traumatisch herinnering en het beangstigende vooruitzicht die bij haar het ondraaglijke lijden veroorzaakten dat haar aanzette tot het opstellen van haar schriftelijke wilsverklaring. Dat lijden verdween echter al voor opname in het verpleeghuis. Haar huisarts rapporteerde hierover bij de toetsingscommissie: 'Toen patiënte een jaar voor het overlijden in cognitief opzicht sneller achteruitging, werd haar lijden minder'. ${ }^{25}$ Dat zou de verklaring kunnen zijn waarom de vrouw uiteindelijk toch koos voor verblijf in het verpleeghuis.

Je zou kunnen veronderstellen dat zij door een verkeerd gebruik van haar cognitieve vermogens ondraaglijk leed toen zij haar schriftelijke wilsverklaring opstelde. Dat is een klassiek stoïcijns inzicht. Ons geestelijke lijden wordt veroorzaakt door onjuiste oordelen over onze trauma's en onze angsten en daaruit volgt dat onze levensplannen veel minder rationeel en coherent zijn dan we zouden willen. De stoïcijnse filosofie leert ons echter ook dat we ons emotionele lijden met onze cognitieve vermogens kunnen verlichten, omdat we tot het rationele inzicht

22 Zie bijvoorbeeld Oordeel 2019-79 waarin de toetsingscommissie het handelen van een arts van het Expertisecentrum Euthanasie zorgvuldig achtte. Het leven van de demente patiënt werd thuis beëindigd nadat hij uit het verpleeghuis was gehaald omdat de verpleeghuisarts de euthanasie niet wilde uitvoeren.

23 Of deze dreiging ook uitkomt, hangt af van de beslissing van de Hoge Raad in deze zaak die ten tijde van het schrijven van dit artikel nog niet was genomen.

24 Zie de schriftelijke wilsverklaring van de patiënte en de verklaring van de dochter van de patiënte in overweging 4.4.1 in het vonnis van de rechtbank (ECLI:NL:RBDHA:2019:9506).

25 Weergegeven in Oordeel 2016-85. Uit dit oordeel blijkt dat de huisarts, de tweede consulent en de toetsingscommissie betwijfelden of deze patiënte wel ondraaglijk leed, maar de arts kreeg het voordeel van de twijfel vanwege 'de tekenen van ernstig lijden' bij de vrouw. Zelf had de vrouw tegenover de arts verklaard dat zij nog niet dood wilde omdat 'het nog niet zo erg was', wat de arts ook in het medisch dossier had vastgelegd (overweging 2.13 in ECLI:NL:TGZRSGR: 2018:165). 
kunnen komen dat er geen goede reden is voor onze angst. ${ }^{26}$ Volgens de stoïcijnse filosofie zijn mensen met een schriftelijke wilsverklaring per definitie wilsonbekwaam ter zake van hun verzoek wanneer dat verzoek is gebaseerd op irrationele angst. De stoïcijnse filosofie wordt nog steeds gebruikt in de cognitieve psychologie. Verander je cognitieve oordelen en je angst en dus ook je lijden worden draaglijk. Cognitieve therapie is het redelijke alternatief voor een schriftelijke wilsverklaring gebaseerd op angst.

Dit betekent niet dat de stoïcijnse filosofie zelfdoding uitsluit. Die filosofie kan juist tot het inzicht leiden dat zelfdoding een rationele handeling is vanwege het zinloze vooruitzicht van een leven in vergetelheid. Dat is volgens de stoïcijnse filosofie geen waardevol leven, omdat daarin het rationele element ontbreekt dat het leven de moeite waard maakt. Volgens deze filosofie mag je geen zelfdoding plegen uit irrationele angst, maar wel uit rationele waardering van je kritische belangen. Dat is echter niet het uitgangspunt van het Nederlandse euthanasierecht. Hulp bij zelfdoding bij voltooid leven is nog steeds verboden; ondraaglijk lijden is een wettelijke zorgvuldigheidseis. Daarom is levensbeëindiging bij mensen met dementie die niet ondraaglijk lijden wettelijk uitgesloten.

Dworkins filosofie is in feite een pleidooi voor hulp bij zelfdoding bij voltooid leven. Om zijn filosofie te kunnen realiseren, is in Nederland een wetswijziging nodig. Je zou nog een stap verder kunnen gaan en ook wettelijk kunnen regelen dat dworkinianen euthanasie kunnen krijgen bij vergevorderde dementie. Uit de schriftelijke wilsverklaring moet dan wel uitdrukkelijk blijken dat deze persoon een weloverwogen aanhanger was van de dworkiniaanse filosofie toen hij of zij nog over al zijn of haar cognitieve vermogens beschikte.

Je mag een dementerende dworkiniaan doden, ook al vindt hij of zij het leven op dat moment heel aangenaam. ${ }^{27}$ Levensbeëindiging mag echter niet bij een dementerende hedonist die altijd de filosofie heeft aangehangen dat de waarde van zijn leven bestaat uit de som van genot en pijn, tenzij die som negatief uitvalt door dementie. ${ }^{28}$ Wanneer je Dworkins filosofie gaat opleggen aan mensen die meer waarde hechten aan hun ervaringsbelangen, dan wordt zijn filosofie een dwangfilosofie. Een dworkiniaanse euthanasie op een dementerende hedonist is moord. ${ }^{29}$

Het Nederlandse euthanasierecht zou veel meer een zelfdodingsrecht kunnen zijn. Tot op zekere hoogte is het Nederlandse recht dat ook. De meeste mensen met dementie die euthanasie krijgen, zouden ook zelfdoding kunnen plegen met hulp van een arts. In bepaalde gevallen gaat het daarbij niet om mensen die ondraaglijk lijden, maar om mensen die hun leven voltooid achten in het vooruitRichard Sorabji, Emotion and Peace of Mind (Oxford: Oxford University Press, 2000), 17 e.v.

27 Dworkin, Life's Dominion, 227-228, 231-232.

28 Dworkin stelt hedonisme en utilisme aan elkaar gelijk (Dworkin, Life's Dominion, 203-204).

29 Er zou empirisch onderzoek kunnen worden gedaan naar de filosofische opvattingen van mensen met een schriftelijke wilsverklaring om te kunnen inschatten wat het percentage hedonisten onder hen is. 
zicht van geestelijke aftakeling. In die gevallen is het Nederlandse euthanasierecht opgerekt buiten zijn wettelijke grenzen en normatieve grondslagen. De ondraaglijkheid van het lijden is dan niet de werkelijke reden voor euthanasie. Dat is de legitieme wens om op waardige wijze te sterven op een moment dat het nog kan. Die wens valt onder het zelfbeschikkingsrecht van deze mensen.

Een dworkiniaan wil nog verder kunnen gaan. Hij wil ook euthanasie in de situatie dat hij volledig dement is geworden, ook al lijdt hij dan niet. ${ }^{30}$ Een hedonist ziet voor die situatie op zich geen reden voor euthanasie, tenzij hij meer zou lijden dan genieten. Ik denk dat ze allebei het fundamentele recht hebben om volgens hun eigen filosofie te worden behandeld, mits volstrekt duidelijk is wat hun filosofie is en zij de consequenties weloverwogen hebben aanvaard. ${ }^{31}$ Mijn bezwaar tegen de dworkinianen is dat zij hun persoonlijk principe verheffen tot het principe van algemene wetgeving. Daardoor nemen zij de rechten van anderen niet serieus. Dat is ook mijn bezwaar tegen de hedonisten die eisen dat een mens moet lijden om euthanasie te kunnen krijgen. Laat iedereen sterven volgens zijn of haar eigen opvattingen. De filosofie van de patiënt is beslissend en niet die van de arts, de wetgever of de filosoof.

30 Een voorbeeld is Henk Blanken, Beginnen over het einde, De Correspondent 2019.

31 De NVVE zou op het standaardformulier van de schriftelijke wilsverklaring de volgende vraag kunnen stellen. Bent u: a. dworkiniaan; b. hedonist; c. anders, namelijk...; d. ik weet het niet. Mensen die $d$. aankruisen krijgen geen euthanasie, want zij hebben nog geen weloverwogen beslissing genomen. Mensen die a., b. of c. aankruisen, worden behandeld volgens hun eigen filosofie. Ik zou zelf $d$. aankruisen. 